\title{
Type 2 Segmental Darier's Disease in a Twelve-Year Old Nigerian Male - a Case Report
}

\author{
"Yusuf S M MBBS, MSC, FWACP"'Mohammed A Z BM BCh, FMCPath, "Uloko A E BM BCh, FMCP. \\ * Dermatology Unit, Department of Medicine, Aminu Kano Teaching Kano Nigeria. *Department of Pathology, \\ Aminu Kano Teaching Hospital Kano Nigeria
}

\begin{abstract}
Darier's disease is an autosomal dominant disorder characterized clinically by presence of keratotic papules in a seborrheic distribution, nail involvement and mucosal lesions. There are several clinical variants of Darier's disease, but few cases of segmental Darier's disease have been described in the literature. We describe a 12year old boy with type 2 mosaic phenotype. This unique clinical variant of Darier's disease has been described very rarely.
\end{abstract}

Keywords: Autosomal dominant, keratotic papules, seborrheic distribution, nail and mucosal involvement.

\section{Date Accepted for publication: 18th August 2009 Nig J Med 2009; 413 - 415 \\ Copyright $\odot 2009$ Nigerian Journal of Medicine}

\section{Introduction}

Darier's disease is an autosomal dominant skin disorder that is characterized by multiple keratotic papules, focal loss of adhesion and abnormal keratinization. There are several clinical variants of Darier's disease including segmental form. Two types of mosaic manifestations can be distinguished in Darier's disease. A type-1 mosaicism reflects a localized postzygotic mutation in an otherwise normal embryo, while a type-2 mosaicism represents a postzygotic mutation eliminating the normal allele at a gene locus, for which the embryo carries a dominant heterozygous germline mutation.

\section{Case report}

A-12year-old boy presented with generalized eruption of 8-years duration. The eruption initially had appeared on the right side of his chest and over the course of months had spread distally to involve the entire trunk, the neck and the extremities. The eruption has remained stable over the past 3 years. There are no associated symptoms. The patient had used several medications without any improvement. There was no history of a similar eruption in any other family members. Physical examination revealed a young boy with generalized and extensive verrucous hyperpigmented skin lesions distributed over the face, neck, trunk (Fig. a \& b) and extremities. The lesions were distributed in a swirled pattern along the lines of Blaschko. On the back of his body, the lesions were found to be diffusely and rather symmetrically disseminated. On the frontal aspect, however, a bandlike pattern of pronounced involvement with concomitant streaks of healthy skin, both following the lines of Blaschko, was noted. Nail examination of the right hand showed white and red longitudinal bands and subungual hyperkeratosis. There was no mucosal involvement.

Haematological examinations, and liver and kidney function tests were within normal limits. Serology for VDRL and HIV antibody was non-reactive.

Skin biopsy from the representative keratotic lesion (shin) showed unusually prominent hyperkeratosis and papillomatosis in the epidermis, intraepidermal acantholysis, lacunae and dyskeratosis in the form of corps ronds and grains (Fig. c), features that were consistent with Darier's disease. As this patient has a more pronounced involvement than the usual Darier's disease lesions, disposed in a segmental arrangement, he probably represents a type 2 segmental manifestation of the disorder.

The patient was prescribed oral retinoids and topical salicylic acid, the former was not available in the country, while the latter was used for 6 months without appreciable response.

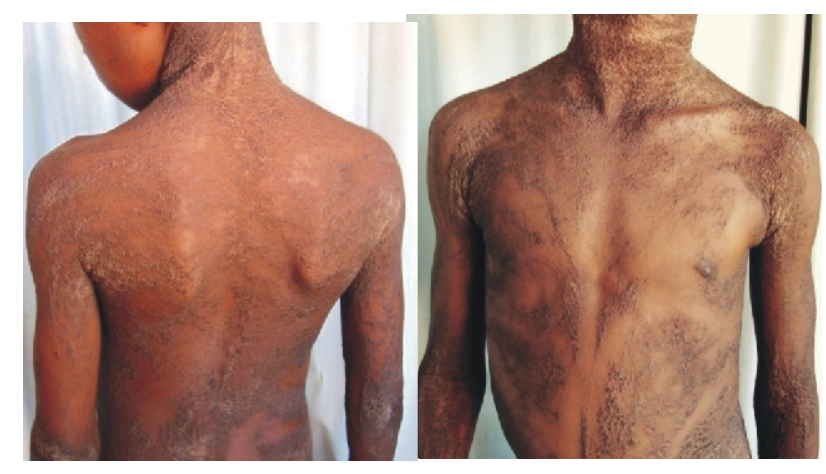

Figure 1\& 2: Extensive verrucous skin lesions along the lines of Blaschko 


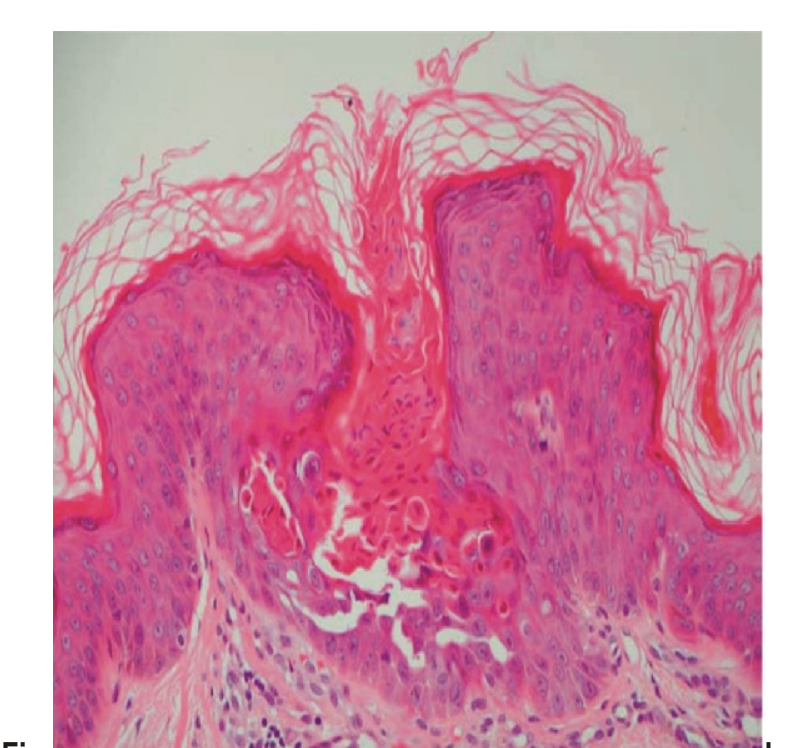

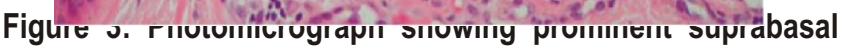
acantholysis. There are marked dyskeratotic keratinocytes and, numerous corps ronds and grains. Hyperkeratosis and acanthosis are also noted

\section{Discussion}

Darier's disease, also known as Darier-White disease or keratosis follicularis, was described independently by Darier and White in $1889 .^{1,2}$ It is an autosomal dominant disorder of abnormal keratinization and acantholysis with involvement of the tonofilament-desmosome complex. The underlying defect is a result of mutations in the ATP2A2 gene on chromosome 12q23-24 that encodes for a sarco/endoplasmic reticulum calcium ATPase pump (SERCA 2) expressed on human skin and mucosa. ${ }^{3}$ Characteristic skin and nail changes consist of bilateral crusted red-brown papules and plaques in a seborrheic distribution, and V-shaped nicking or longitudinal ridging of the nails. ${ }^{4}$ Reported exacerbating factors for Darier's disease include heat and sweating, sunlight, emotional stress, menstruation, pregnancy, drugs such as lithium. 4,5

Various forms of Darier's disease are recognized including vesicobullous, cornifying, acral, comedonal, linear/limited, haemorrhagic and hypopigmented or

\section{References}

1. Darier J. De la psorospermose folliculaire végétante. Ann Dermatol Syphiligr 1889; 10: 597-612.

2. White J. A case of keratosis (ichthyosis) follicularis. J Cutan Genito-Urinary Dis 1889; 7:210-2119.

3. Sakuntabhai A, Ruiz-Perez V, Carter S. Mutations in ATP2A2,encoding a Ca2+ pump, causeDarier disease. Nat Genet 1999; 21: 271-277. depigmented variants. ${ }^{4,6}$ In linear cases, a segmental distribution of this disease may be present in which localized lesions, found along the lines of Blaschko, are otherwise indistinguishable from those of generalized Darier's disease. Two types of segmental manifestations mosaic forms of this autosomal dominant skin disease exist. ${ }^{7}$ Type-1 mosaicism reflects a localized postzygotic mutation in an otherwise normal embryo. This mutation leads to a localized population of heterozygous cells, resulting in segmental disease where the skin outside the segmental disorder is normal. The type 2 segmental manifestations results from loss of the corresponding wildtype allele occurring in a heterozygous embryo and reflects either homozygosity or hemizygosity for the underlying mutation, giving rise to rather pronounced segmental lesions that are superimposed on the ordinary nonsegmental phenotype. ${ }^{8}$ This is due to a germline mutation of the gene after a postzygotic mutation leading to double inactivation of the gene. The severe linear manifestation then reflects a doubling of the genetic burden. ${ }^{7,8}$

Differential diagnoses of Darier's disease include eczema, Hailey-Hailey disease, Grover's disease for seborrhoeic or flexural disease, acantholytic epidermal nevus for linear or segmental lesions, acrokeratosis verruciformis of Hopf and plane wart for acral lesions. ${ }^{4}$

The primary aim of treatment in Darier's disease is controlling skin irritation with emollients, soap substitutes, and keeping the skin cool by wearing comfortable cotton clothing. Sunblock is recommended for those with a history of photoaggravation. ${ }^{9}$ Topical retinoids such as tazarotene or adapalene may be sufficient for patients with mild or linear disease. ${ }^{9,10}$ Oral retinoids maybe more effective if combined with topical retinoids. ${ }^{11}$ Laser treatment is also advocated. ${ }^{12}$

4. Judge MR, McLean WHI, Munro CS. Darier's disease and related disorders. In: Burns T, Breathnach S, Cox N, Griffiths $\mathrm{C}$, eds. Rook's textbook of dermatology, 7th edition, volume two. Massachusetts, Oxford, Victoria: Blackwell Science, 2004: 34.6934.71.

5. Goldsmith LA, Baden HP. Darier-white disease (Keratosis Follicularis) and acrokeratosis verruciformis. In: Freedberg IM, Eisen AZ, Wolff K, Austen KF, Goldsmith LA, Katz SI, Fitzpatrick TB. Fitzpatrick's dermatology in general medicine, 5th edition. USA: McGraw-Hill, 1999: 614619. 
6. Burge SM, Wilkinson JD. Darier-White disease: a review of the clinical features in 163 patients. J Am Acad Dermatol. 1992 Jul;27:40-50.

7. Peter H. Itina,b, Stanislaw A. Büchnera, Rudolf Happle.Segmental Manifestation of Darier Disease. Dermatol, 2000;200:254-257

8. Sakuntabhai A, Dhitavat J, Burge S. Mosaicism for ATP2A2 Mutations Causes Segmental Darier'sDisease. J Invest Dermatol 2000; 115: 1144-7.

9. Cooper SM, Burge SM. Darier's disease: epidemiology, pathophysiology, and management. Am J Clin Dermatol. 2003:4:97-105.
10. Dicken $\mathrm{CH}$, Bauer EA, Hazen PG. Isotretinoin treatment of Darier's disease. JAmAcad Dermatol 1982; 6: 721-6.

11. Hur KH, Kim HO, Park SR. A case of Darier's disease treated by the combined treatment with oraletretinate and topical tretinoin cream. Korean J Dermatol 1995; 33: 764-8.

12. Beier C, Kaufmann R. Efficacy of erbium:YAG laser ablation in Darier disease and Hailey-Haileydisease. Arch Dermatol 1999; 135: 423-7. 